\title{
Study of Common Infections among Children with Sickle Cell Anaemia in Saudi Arabia
}

Sidieg Sheikheldin Elobied ${ }^{\mathrm{a}}$, Ismail A. Ramadan ${ }^{\mathrm{a}}$, Ghada S. Abdelmotaleb ${ }^{\mathrm{a}}$, Abd elmoniem A. Younis ${ }^{b}$

a Department of pediatrics, Benha faculty of medicine, Banha University, Egypt.

b Department of Puplic Health and Community Medicine, Benha Faculty of MedicineBenha University.

Correspondence to: Sidieg Sheikheldin Elobied, Department of pediatrics, Benha faculty of medicine, Banha University, Egypt.

Email:

aburaheeg@hotmail.com

Received: 4 March 2020

Accepted: 6 August 2020

\section{Abstract:}

Sickle cell disease (SCD) is a collective term for a number of genetic disorders in which hemoglobin is structurally abnormal, resulting in the episodic formation of sickle-shaped red blood cells (RBCs) and a wide range of clinical manifestations. Aims: To identify the common infections in children with sickle cell disease in Kingdom of Saudi Arabia regarding its prevalence, infection sites, as well as type of pathogens. Methods and Material: This was cross-sectional study conducted on 100 sickle cell disease patients who attended emergency department, King Abdulla Hospital, KSA. All children with SCD presenting with symptoms and signs suggestive of infections or acute complications of sickle cell anaemia were included e.g. fever, cough, pain, burning micturition, swelling, bonny tenderness. The identification of the infecting organism was done by culture studies. Results: Patients' age ranged from 2 to 18 years old with a mean of $13.12 \pm 4.85$ (SD); 68 patients were females and 32 were males while, $95 \%$ of patients had positive family history of consanguinity. Nine (9\%) and $12(12 \%)$ cases had positive blood and urine cultures. Out of the 21 positive microbial infection cases, 12 cases were diagnosed as Urinary Tract Infection, 4 cases as Osteomyelitis, 2 cases as Fever for investigation and 3 cases as Sepsis. All cases of pneumonia were diagnosed clinically (no positive microbial blood culture cases). Two of the Osteomyelitis cases were Staphylococcus species and the other 2 were Salmonella. In all cases diagnosed as Fever for investigation and Sepsis, the organism was Staphylococcus species. In cases diagnosed as Urinary Tract Infection; 7 of them were E. coli and 5 were Klebsiella pneumonia. Conclusions: Urinary tract infection was the most common infection in our study. E. Coli was the most common organism isolated followed by Staphylococcus species, Klebsiella pneumonia and Salmonella spcs

Key words: Sickle Cell Anemia, Common Infections, children. 


\section{Introduction:}

Sickle cell disease (SCD) is one of the most prevalent genetic disorders. There are approximately 300 million carriers of sickle cell trait worldwide [1]. It is an inherited condition of universal distribution and its most common clinical manifestation is anaemia due to chronic haemolysis [2].

Upon exposure to low oxygen tension the mutant haemoglobin $\mathrm{S}$ becomes less soluble and aggregates into large polymers, this results in a distorted erythrocyte with marked decrease in its deformability contributing to the vaso-occlusive and haemolytic aspects of the disease [3].

Sickle cell disease is characterized by an increased susceptibility to infections. Patients with SCD can develop specific and sometimes life-threatening complications as well as extensive organ damage reducing both their quality of life and their life expectancy [4]. Increased risk of severe bacterial infections due to loss of functioning spleen tissue is comparable to the risk of infections after having spleen removed surgically. Patients with SCD have an increased susceptibility to infection particularly with encapsulated organisms: Streptococcus Pneumonia, Haemophilus influenza, Salmonella Spp. [5].
Before the systematic use of vaccines and prophylactic penicillin, bacterial infections were the leading cause of death in young children with SCD. Nevertheless, despite the prophylactic program, infections are still a

significant cause of morbidity in older patients [6].

Information about the prevalence of SCD in Saudi Arabia is patchy, but studies have reported that $\mathrm{SCD}$ is a relatively common genetic disorder in that part of the world. The carrier status for SCD ranged from $2 \%$ to $27 \%$, and up to $1.4 \%$ had $\mathrm{SCD}$, in some areas. These estimates of frequency are not based on new born screening and probably underestimate the frequency of SCD [7].

This present study aimed at studying the common infections in children with sickle cell disease regarding its occurrence, infection sites, as well as the causative pathogens.

\section{Patients and methods}

This was prospective cross -sectional study during period from August 2015 to February 2017. The study was conducted on 100 sickle cell disease patients came to the 
emergency department, King Abdulla Hospital, Bisha - KSA. Inclusion criteria: all children with SCD in the age group 2-18 years, presenting with symptoms and signs suggestive of infections e.g. fever, cough, pain, burning micturition, swelling, bonny tenderness. Exclusion criteria were patients with SCD, if associated with other immunecompromised disorders, like DM, nephrotic syndrome and acute combined immunodeficiency or immune-suppressed by drugs, like steroids, or patients on antimicrobial therapy, within 7 days from presentation.

\section{Data collection:}

Informed consents had been taken from parents of all patients participated in our study and the following data were collected:

(A) Full history taking, including: Name, age, gender, residence, presenting complaint (onset, duration), other symptoms suggestive of infection or acute complications of sickle cell disease, past history of hospitalization, past history of blood transfusion, past history of surgery (e.g. splenectomy), family history of SCD or consanguinity, drug history and vaccination history.

(B) Full clinical examination: General examination (Vital signs, weight and height, pallor, jaundice or swelling) and full systemic examination (Respiratory system to detect signs of infection, cardiovascular system to detect complications of sickle cell anaemia, abdominal examination to detect enlargement of liver and spleen and also scar of splenectomy, central nervous system to detect complications of sickle cell anaemia and musculoskeletal system to detect swellings or tenderness).

(C)Investigations: Complete blood count with differential, reticulocyte count, liver function tests (ALT, AST, bilirubin \{direct and indirect $\}$ and albumin), ESR, CRP, LDH, serum ferritin, BUN and serum creatinine, blood culture and sensitivity, urine culture and sensitivity and ABG. Chest X-ray, other skeletal X-rays, ultrasonography to detect site of infection, ECG \& Echocardiography were also done if needed.

\section{Statistical analysis:}

The collected data were coded then entered and analysed using the SPSS version 20 (Statistical package for social science), description of quantitative variables in the form of mean and standard deviation (mean $\pm \mathrm{SD})$. The following tests of significance were done: Independent-samples t-test of significance was used when comparing between two means, Chi-square (X2) test of significance was used in order to compare proportions between two qualitative parameters, Binary logistic regression: was used to predict the outcome of categorical variable based on one or more predictor 
variables. P-value <0.05 was considered significant. Graphs were used to illustrate simple information.

\section{Ethical considerations:}

An approval to the study from Ministry of Health (M.O.H) in Bisha, Kingdom of Saudi Arabia (K.S.A) and administration of king Abdulla Hospital (K.A.H) as well as department of paediatrics in K.A.H. were obtained. The protocol was approved by ethical committee, Benha faculty of medicine, Egypt.

\section{Results}

Patients' age ranged from 2 to 18 years old with mean of $13.12 \pm 4.85$ years. Of the studied population, 68 patients were females while 32 were males. Regarding family history of consanguinity, $95 \%$ of patients had positive family history. The presenting complains of the studied population were $52 \%$ of them presented with fever, $30 \%$ with pain, $17 \%$ with cough, $12 \%$ were presented with Burning micturition, $8 \%$ with swelling and only one patient (1\%) presented with dizziness (fig.1).

Regarding onset of the disease, $80 \%$ of our studied population had gradual onset while $20 \%$ had sudden onset. The disease duration ranged from 1 to 7 days with a mean of
$4.07 \pm 1.42$ days. Out of the 100 studied patients; 91 patients had previous hospital admission due to vaso-occlusive crisis (VOC), 28 patients were previously admitted to hospital due to Haemolytic crisis, 9 patients were previously hospitalized due to splenic sequestration crisis, 3 patients with acute abdomen, one patient with sepsis, one with febrile illness and one with pneumonia. Only one patient of our studied population had no history of blood transfusion while the remaining 99 cases had history of blood transfusion [78 out of 99 cases due to Haemolytic crisis, 38 due to VOC, 9 due to splenic sequestration crisis, 4 cases for aplastic crisis, 3 cases for hyper-transfusion, 2 cases for sepsis and another 2 cases for cerebrovascular accident (CVA)]. All patients in our studied population (100\%) had folic acid in their treatment regimen, 79 patients received Hydroxyurea, 18 patients received Penicillin V, 3 patients were on Aspirin, one cardiac patient was on Captopril and another cardiac patient was on Digoxin.

Regarding history of previous vaccination; $68 \%$ of the studied cases had Pneumococcal and Meningococcal vaccines, while 32\% hadn't receive special vaccination, 27 had Influenza vaccine and only one patient had 
received HIB vaccine. Vital signs at time of

Among the studied cases; 98\% had pallor; $50 \%$ had jaundice and $8 \%$ had musculoskeletal swelling. Regarding systemic examination; chest examination revealed bilateral crepitation in $17 \%$ of cases. By examining the abdomen; $21 \%$ of patients had Hepatomegaly, 9\% had Scar of splenectomy (due to splenic sequestration crisis), 3\% had tenderness around the umbilicus and only one patient (1\%) had Splenomegaly. By examining the CNS; 7 cases had Hemiplegia and 3 cases were with paraplegia. Musculoskeletal system examination revealed swelling with tenderness in 8 cases ( $8 \%$ ) and weakness in 3 cases. Blood culture were positive only in $9(9 \%)$ cases ( 4 cases Osteomyelitis, 2 cases as Fever for investigation and 3 cases Sepsis).Urine culture was positive in 12 hospitalization of cases is shown in table (1). cases(12\%); 7 cases were E. Coli and 5 were Klebsiella Pneumonia (table 2,4).

More than half of the studied cases had normal chest X-ray and $24 \%$ of the studied cases had no chest X-ray during their admission. 12 cases showed Pneumonia, 2 cases showed Collapse consolidation, 2 cases had lung mass and only one case was with soft tissue mass. All cases of pneumonia were diagnosed clinically (no positive microbial blood culture cases) (table 3).

According to binary logistic multiregression analysis for microbial and other parameters, Burning micturition, temp, swelling with tenderness, Neutrophils count and UTI were statistically significant predictors risk factors for positive microbial infection in the studied patients (table 5 and fig. 2).

Table (1): Vital signs of cases

\begin{tabular}{ll}
\hline Vital signs & Mean \\
\hline Temp & $36-39.5(37.45 \pm 0.86)$ \\
$\mathrm{RR} / \mathrm{m}$ & $15-60(22.39 \pm 5.74)$ \\
$\mathrm{HR} / \mathrm{m}$ & $25-145(95.63 \pm 20.25)$ \\
Oxygen Saturation & $78-99(94.38 \pm 3.97)$ \\
Systolic BP & $87-138(106.58 \pm 19.05)$ \\
Diastolic BP & $50-96(66.25 \pm 9.25)$ \\
WT/kg & $3.8-60(27.25 \pm 11.11)$ \\
\hline
\end{tabular}


Table (2): Blood and urine culture results of the study group

\begin{tabular}{ll}
\hline Blood culture & Total $(\mathbf{N}=\mathbf{1 0 0})$ \\
\hline Negative & $91(91.0 \%)$ \\
Positive & $9(9.0 \%)$ \\
& $7(7.0 \%)$ Staphylococcus species \\
Type of Organisms & $2(2.0 \%)$ Salmonella \\
Urine culture & Total $(\mathbf{N}=\mathbf{1 0 0})$ \\
Negative & $88(88.0 \%)$ \\
Positive & $12(12.0 \%)$ \\
Type of Organisms & $7(7.0 \%)$ E.coli \\
& $5(5.0 \%)$ Klebsiella pneumonia \\
\hline
\end{tabular}

Table (3) : Diagnosis of the studied cases

\begin{tabular}{lcc}
\hline \multicolumn{1}{c}{ Diagnosis } & Total $(\mathbf{N = 1 0 0 )}$ & $\begin{array}{c}\text { Positive microbial } \\
\text { infection (N=21) }\end{array}$ \\
\hline Vaso-occlusive crisis & $30(30 \%)$ & --- \\
Pneumonia & $17(17 \%)$ & --- \\
Haemolytic crisis & $16(16 \%)$ & --- \\
UTI & $12(12 \%)$ & $12(57.1 \%)$ \\
Osteomyelitis & $8(8 \%)$ & $4(19 \%)$ \\
Fever for investigation & $7(7 \%)$ & $2(9.5 \%)$ \\
Sepsis & $6(6 \%)$ & $3(14.3 \%)$ \\
Abscess & $2(2 \%)$ & --- \\
Aplastic Crisis & $2(2 \%)$ & --- \\
\hline
\end{tabular}

NB: All cases of pneumonia were diagnosed clinically (no positive microbial blood culture).

Table (4): Type of organisms regarding diagnosis

\begin{tabular}{lcc}
\hline Diagnosis & Number of cases & Type of Organism \\
\hline Osteomyelitis & 2 & Staphylococcus species \\
Fever for investigation & 2 & Salmonella \\
Sepsis & 2 & Staphylococcus species \\
& 3 & Staphylococcus species \\
Urinary Tract Infection & 7 & E.coli \\
\hline
\end{tabular}


Table (5): Logistic regression of positive risk factors affecting microbial infection

\begin{tabular}{lcccccc}
\hline & \multirow{2}{*}{ B } & \multirow{2}{*}{ S.E. } & Sig. & \multirow{2}{*}{$\operatorname{Exp}(\mathbf{B})$} & \multicolumn{2}{c}{ 95\% C.I } \\
Lower & Upper \\
\hline Burning micturition & -2.220 & 0.136 & 0.026 & 0.993 & 0.338 & 1.589 \\
Temperature & 0.292 & 0.277 & 0.037 & 0.951 & 0.323 & 1.522 \\
Swelling with tenderness & -0.950 & 0.058 & 0.011 & 0.425 & 0.144 & 0.679 \\
Neutrophils & -0.630 & 0.039 & 0.007 & 0.282 & 0.096 & 0.452 \\
UTI & -0.129 & 0.017 & 0.005 & 0.107 & 0.036 & 0.171 \\
\hline
\end{tabular}

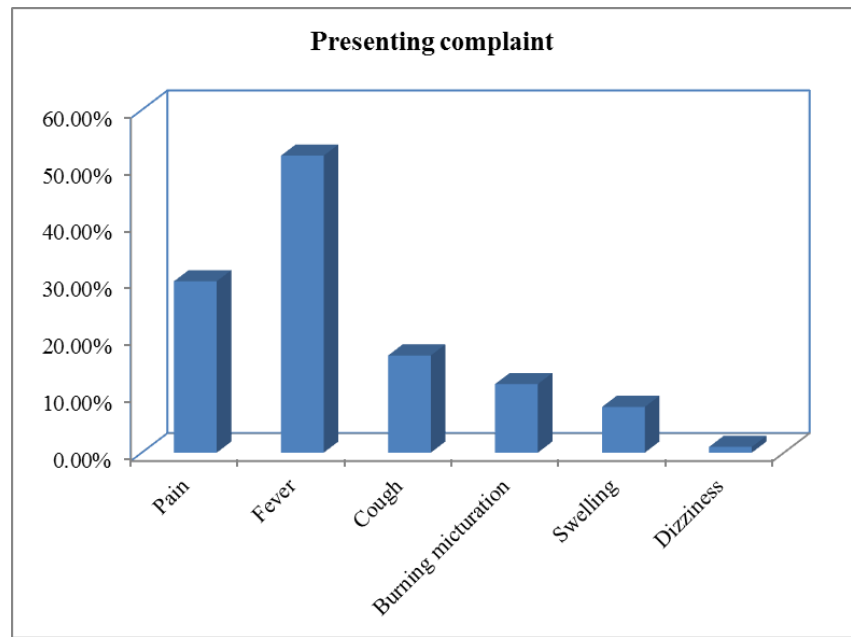

Fig (1): Presenting complaint of the study cases.

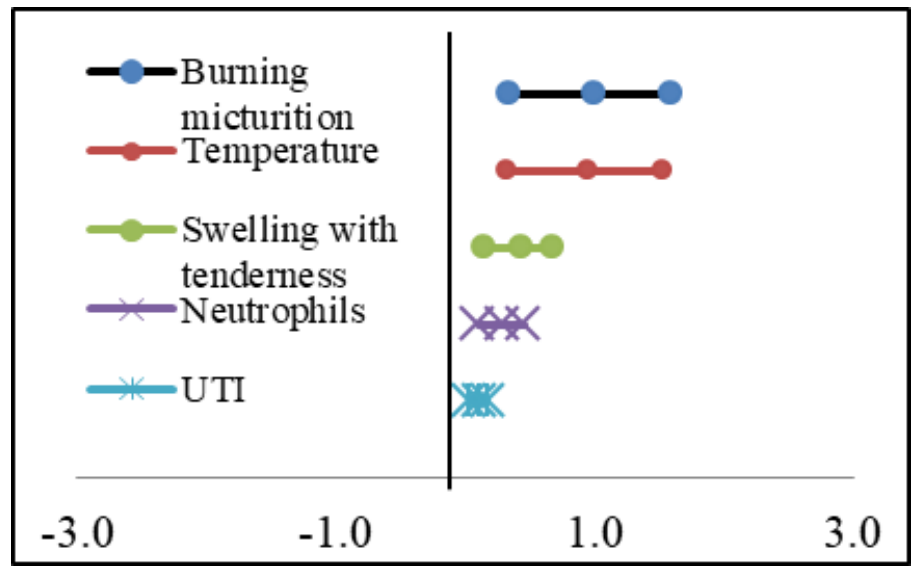

Fig (2): Odd Ratio of positive risk factors affecting microbial infection. 



\section{Discussion}

Acute infections are the major cause of morbidity and mortality among SCD children and adults [8], but there remains a crucial dearth of data regarding its burden in MENA region countries such as KSA. We aimed to study the common infections in children with sickle cell disease regarding occurrence, infection sites and causative pathogens in the emergency department in king Abdulla hospital, Bisha-KSA from (August 2015 to February 2017).

Results from the present cross-sectional study on 100 SCD patients from all age groups and both sexes, females were more dominant in our study; with female: male ratio 2.1:1which, was high compared with study in India where males were higher than females with female to male ratio 1:1.5 [9]. Regarding family history of consanguinity, $95 \%$ of patients had positive family history, which was in harmony with most of the previous researches as they demonstrated the association of SCA with parental consanguinity concluded that the populations with high consanguinity marriages rates have significantly higher incidence of inherited blood disorders such as sickle cell anaemia [10]. It has been shown that the high rate for consanguinity marriages in Saudi Arabia which, accounts more than $50 \%$, with the rate of marriage between first cousins ranging from $40 \%$ to $50 \%$, are related to traditional and social factors to keep property within families [11]. This cross-sectional study demonstrates tremendous clinical variability in the presentation of patients with SCD in emergency room. The onset of the symptoms in $80 \%$ of our studied population was gradual while in $20 \%$, it was sudden onset and the duration ranged from 1 to 7 days (mean of $4.07 \pm 1.42$ days).

The most frequent presenting compliant of our study group was fever (52\%) followed by pain (30\%). However high fever (e.g., $>101-101.5^{\circ} \mathrm{F}$ ) is a medical emergency in patients with $\mathrm{SCD}$, because it can be the first sign of bacteremia [12].

This finding went hand in hand with the report of Vichinsky and his colleges that young children commonly present in emergency room with fever and cough and less frequently have pain [13].

This study showed that SCD patients are recurrently admitted to hospitals; $91 \%$ of our studied population was previously admitted to hospital due to vaso-occlusive crisis and $28 \%$ was admitted due to haemolytic crisis; this finding is not unique to our hospital where a study conducted in Atlanta, USA 
published in 2010 about the frequency of accident and emergency visits by SCD patients had a similar findings. They found that on average, approximately 197,333 of emergency department visits each year from 1999 and 2007 were SCD patients [14]. VOC was the most common cause of inpatient hospitalizations of SCD patients in the present study (91\%). This finding supports results reported by Akar and Adekile in Kuwait [15], Jaiyesimi et al. in Oman [16] and Brown et al. in Nigeria [17]. Frequent VOC requiring hospitalization is one of the characteristic features of SCD [18].

Blood transfusion is commonly used in the comprehensive management of SCD patients; in our study $99 \%$ of patients reported previous blood transfusion; $78.79 \%$ due to haemolytic crisis and $38.38 \%$ due to V.O.C. These findings were in line with studies suggesting that the most common cause of blood transfusion in patients with SCD include: chronic splenic sequestration; severe or lasting aplastic crises, vasoocclusive crisis, acute stroke, acute chest syndrome and haemolytic episodes [19-21]. Early treatment with blood transfusions to lower $\mathrm{HbS}$ levels could help preserve splenic function. However, these therapies are themselves associated with considerable risks, side effects, and practical difficulties, making their routine use inappropriate [8].

Only 9 cases in our studied population had surgical splenectomy, and the indication of splenectomy in all of them was recurrent splenic sequestration crisis, other studies in addition to recurrent acute splenic sequestration crisis; found also splenic abscess, hypersplenism, splenomegaly with a non-functioning spleen and massive splenic infarction to be less common indications for splenectomy [22].

All patients in this studied population (100\%) had folic acid in their treatment regimen. Folic acid replenishes the depleted folate stores necessary for erythropoiesis. So, it well established in the treatment of chronic haemolytic anaemia. Although it is proposed that folate in anaemia raises haemoglobin levels and helps provide a healthy reticulocyte response [21]. In a recent study to analyse the efficacy and possible adverse effects of folate supplementation in people with sickle cell disease; they concluded that there was some evidence that in SCD folate supplementation may improve serum folate concentrations; however, it is unclear if folate supplementation has any effect on haemoglobin concentration, growth, minor infections, major infections, acute splenic 
sequestration, dactylitis or episodes of bone or abdominal pain .The other effects (positive and negative) of folate supplementation remain unclear, and more trials with larger cohorts are needed to determine these [23].

Out of 100 patients in our study, 79 patients received hydroxyurea, as it is the only agent that the Food and Drug Administration (FDA) has approved for the management of SCD, who have had at least three painful crises in the previous 12 months. Hydroxyurea has multiple effects that may contribute to its efficacy in sickle cell disease (SCD). These include increased production of fetal hemoglobin $(\mathrm{HbF})$ with a concomitant reduction in the intracellular concentration of $\mathrm{HbS}$, which affects the polymerization of deoxygenated $\mathrm{HbS}$. This results in decreased hemolysis with the release of free hemoglobin (a contributor to endothelial dysfunction) and an increase in total hemoglobin concentration [24]. The National Heart, Lung, and Blood Institute (NHLBI) issued recommendations in 2002 supporting the use of hydroxyurea in the treatment of children with SCD [25].

Prophylaxis with penicillin is indicated for patient with SCD. In the present study, 18 patients received penicillin $\mathrm{V}$ as a prophylactic antibiotic. Current recommendations state that oral penicillin $\mathrm{V}$ should be commenced at 3 months, as levels of protective fetal haemoglobin (which prevents sickling by inhibiting $\mathrm{HbS}$ polymerization) decline and splenic hypo function begins to develop. A dose of 62.5 $\mathrm{mg}$ twice daily is used for infants less than 1 year, $125 \mathrm{mg}$ twice daily for those aged 1-5 years, and $250 \mathrm{mg}$ twice daily in those aged above 5 years [26].

Among the 100 patients in our study; 68 patients had received vaccine 68 (68\%) for the Pneumococcal and Meningococcal vaccines, 27 (27\%) for the Influenza vaccine in addition to pneumococcal and meningococcal vaccines, and only one patient had received the Haemophilus influenza type $b$ vaccine in addition to pneumococcal and meningococcal vaccines; while $32 \%$ had received no special vaccine. Those findings were higher than what was reported by Anastasie and his colleagues. They were detecting the burden and spectrum of bacterial infections among sickle cell disease children living in Cameroon and found that only 13 (18.8\%) had received the Pneumococcal and Meningococcal vaccines, and 12 (17.4\%) received the Haemophilus influenza type $b$ vaccines; while 58 children $(84.1 \%)$ had received no vaccine [27].Immunizations in 
children with SCD should include all regular vaccines, with the addition of the flu vaccine yearly after six months of age; pneumococcal vaccine at two and five years of age; and, possibly, meningococcal vaccine [28].

An Indian study reported that out of 100 cases, 9 were blood culture positive cases and out of the 9 positive cases, bacteria isolated were Staphylococcus Aureus in 7 cases $(7 \%)$, and Salmonella in 2 cases $(2 \%)$. It could be argued that the predominance of Staphylococcus Aureus, and Salmonella sp. simply reflects high levels of carriage of these organisms in the environment [29]. However our results were much lower than the Indian study where out of 100 cases, 27 were blood culture positive cases with Klebsiella pneumonia in (51.85\%), E-Coli in (14.81\%), Enterococcus in (7.40\%), Salmonella in $(7.40 \%)$, Streptococcus Pneumonia in $(3.70 \%)$, Staphylococcus aureus in (11.11\%), and Acinetobacter in $(3.70 \%)$ [9].

Twelve cases (12\%) having urinary tract infection showed bacterial growth on urine culture, the organism isolated was $E$. coli in a 7 patients and Klebsiella pneumonia in 5 of them. these were higher than the reported in a similar study where only 2 cases (2\%) showed bacterial growth on urine culture and the organism isolated was E. coli [9] In the present study, pneumonia was present in $17 \%$ of cases, which were lower than the reported in a similar study carried out in India in 100 patients to study prevalence and type of infections in sickle cell disease patients where the prevalence of pneumonia was in $37 \%$ [9].

In this, the incidence of VOC was $30 \%$ and it was significantly lower with positive microbial infection ( $\mathrm{p}$-value0.016); these findings were lower than a similar study $(83.3 \%)$ conducted to detect Burden and spectrum of bacterial infections among sickle cell disease children living in Cameroon [27].

Osteomyelitis is the most common type of joint infection in SCD, found in up to $61 \%$ of patients [30]. It is usually triggered by vaso-occlusive crises; the incidence of osteomyelitis cases was $8 \%$ in the present study without statistically significant differences between positive and negative microbial culture ( $\mathrm{p}$-value> 0.05), which was higher than the reported in a similar study where the incidence was $2 \%$ [9].

Incidence of septicaemia was $6 \%$ in present study, which was high as compared to the Indian study $1 \%$ [9], however our finding 
still lower than another study (23\%) [31]. Sepsis was significantly higher with positive microbial infection $(\mathrm{p}$-value $=0.009)$.

In the present study, skin/ soft tissue infection (Abscess) was seen in $2 \%$ cases, that was comparable to the $4 \%$ cases reported in a similar study [9].

\section{Conclusion}

Despite the availability of many antibiotics and effective vaccinations that have greatly treat and reduced infection complications in SCD, infection remains a major cause of morbidity in our countries especially in children. In this present study Urinary tract infection was the most common infection in the studied population especially with $E$. coli followed by staphylococcus species, Klebsiella pneumonia and Salmonella.

\section{References}

[1]Bunn HF (2013): The triumph of good over evil: protection by the sickle gene against malaria. Blood; 121:20

[2] Gumiero A P, Bellomo-Brandao M A, and CostaPinto E A (2008): Gallstones in children with sickle cell disease followed up at a Brazilian haematology center. Arq Gastroenterol; 45(4): 313-318.

[3] Embury SH, Matsui NM, Ramanujam S, Mayadas TN, Noguchi CT, Diwan BA, Mohandas N and Cheung AT (2004): The contribution of endothelial cell p-selectin to the micro vascular flow of mouse sickle erythrocytes in vivo. Blood, 104(10):33783385 .

[4] Schnog JB, Duits AJ, Muskiet FA, Rojer RA (2004): Sickle cell disease a general overview. Netherlands J Med; 62(10):364-374.

[5] Magnus, S. A., Hambleton, I. R., Moosdeen, F., \& Serjeant, G. R. (1999): Recurrent infections in homozygous sickle cell disease. Archives of disease in childhood, 80(6), 537-541.

[6] Gill FM, Sleeper LA, Weiner SJ, Brown AK, Bellevue R, Grover R, et al. (1995): Clinical events in the first decade in a cohort of infants with sickle cell disease. Blood; 86(2):776-783.

[7] Al-Qurashi, M. M., El-Mouzan, M. I., AlHerbish, A. S., Al-Salloum, A. A., \& Al-Omar, A. A. (2008): The prevalence of sickle cell disease in Saudi children and adolescents. A community-based survey. Saudi medical journal, 29(10), 1480-1483.

[8] Booth, C., Inusa, B., \& Obaro, S. K. (2010): Infection in sickle cell disease: a review. International Journal of Infectious Diseases, 14(1), e2-e12.

[9] Shinde S, Bakshi AP, Shrikhande AV (2015): Infections in sickle cell disease. IAIM,; 2(11) 26-34.

[10] Memish ZA, Saeedi MY (2011): Six-year outcome of the national premarital screening and genetic counselling program for sickle cell disease and $\beta$-thalassemia in Saudi Arabia". Annals of Saudi Medicine 31 (3): 229-35. Doi:10.4103/02564947.81527. PMC 3119961. PMID 21623050. 
[11] Yawn BP, Buchanan GR, Afenyi-Annan AN, Ballas SK, Hassell KL, (2014) : Management of sickle cell disease: summary of the 2014 evidencebased report by expert panel members.JAMA 312: 1033-1048.

[12] McCavit, T. L., Xuan, L., Zhang, S., Flores, G., \& Quinn, C. T. (2012): Hospitalization for invasive pneumococcal disease in a national sample of children with sickle cell disease before and after PCV7 licensure. Pediatric blood \& cancer, 58(6), 945-949. Mekontso Dessap, A., Leon, R., Habibi, A., 2008. Pulmonary hypertension and corpulmonale during severe acute chest syndrome in sickle cell disease. Am. J. Respir.Crit. Care Med. 177 (6), 646653.

[13] Vichinsky EP, Neumayr LD, Earles AN, Williams R, Lennette ET, Dean D, et al., (2000): Causes and outcomes of the acute chest syndrome in sickle cell disease. N Engl J Med; 342:1855-65.

[14] Hussain R. Yusuf, Hani K. Atrash, Scott D. Grosse, Christopher S. Parker, Althea M. Grant (2010): Emergency Department Visits Made by patients with Sickle Cell Disease :A descriptive Study,1999-2007, American Journal of Preventive Medicine, Volume 38,Issue 4,Supplement, Pages S536-S541,ISSN 0749-3797.

[15] Akar, N. A., \& Adekile, A. (2008): Ten-year review of hospital admissions among children with sickle cell disease in Kuwait. Medical Principles and Practice, 17(5), 404-408.

[16] Jaiyesimi, F., Pandey, R., Bux, D., Sreekrishna, Y., Zaki, F., \& Krishnamoorthy, N. (2002): Sickle cell morbidity profile in Omani children. Annals of tropical paediatrics, 22(1), 45-52.
[17] Brown, B. J., Jacob, N. E., Lagunju, I. A., \& Jarrett, O. O. (2013): Morbidity and mortality pattern in hospitalized children with sickle cell disorders at the University College Hospital, Ibadan, Nigeria. Nigerian Journal of Pediatrics, 40(1), 34-39.

[18] Krishnamurti, L., Smith-Packard, B., Gupta, A., Campbell, M., Gunawardena, S., \& Saladino, R. (2014): Impact of individualized pain plan on the emergency management of children with sickle cell disease. Paediatric blood \& cancer, 61(10), 17471753.

[19] Aliyu, Z. Y., Kato, G. J., Taylor, Jt., Babadoko, A., Mamman, A. I., Gordeuk, V. R. (2008): Sickle cell disease and pulmonary hypertension in Africa: A global perspective and review of epidemiology, pathophysiology, and management. American Journal of Hematology, 83(1), 63-70. http://dx.doi.org/10.1002/ ajh.21057. Epub 2007/10/03. PubMed PMID: 17910044.

[20] Kolapo, K. O., \& Vento, S. (2011): Stroke: A realistic approach to a growing problem in subSaharan Africa is urgently needed. Tropical Medicine \& International Health, 16(6), 707-710. http://dx.doi.org/10.1111/j.1365-3156.2011.02759.x. Epub 2011/05/12. PubMed PMID: 21557793.

[21] Stuart MJ, Nigel RL (2004): Sickle-cell disease. Lancet; 364:1343-60. Part I: sickle cell disease. Exp Rev MolBiol 2006;8:

[22] Al-Salem, A. H. (2006): Indications and complications of splenectomy for children with sickle cell disease. Journal of pediatric surgery, 41(11), 1909-1915. 
[23] Dixit, R., Nettem, S., Madan, S. S., Soe, H. H. K., Abas, A. B., Vance, L. D., \& Stover, P. J. (2016): Folate supplementation in people with sickle cell disease. The Cochrane database of systematic reviews, 2, CD011130.

[24] Kato, G. J., Gladwin, M. T., \& Steinberg, M. H. (2007): Deconstructing sickle cell disease: reappraisal of the role of hemolysis in the development of clinical sub phenotypes. Blood reviews, 21(1), 37-47.

[25] Kavanagh PL, Sprinz PG, Vinci SR, Bauchner H, Wang CJ (2011): Management of children with sickle cell disease: a comprehensive review of the literature". Paediatrics 128 (6): e155274. Doi:10.1542/peds.2010-

3686. PMID 22123880.

[26] Dick, M. (2010): Sickle cell disease in childhood: standards and guidelines for clinical care. NHS Sickle Cell and Thalassemia Screening Programme.

[27] Alima Yanda, A. N., Nansseu, J. R. N., Mbassi Awa, H. D., Tatah, S. A., Seungue, J., Eposse, C., \& Koki, P. O. N. (2017): Burden and spectrum of bacterial infections among sickle cell disease children living in Cameroon.
BMC Infectious Diseases, 17(1), 211. Doi: 10.1186/s12879-017-2317-9.

[28] Centers for Disease Control and Prevention (2007 ): Sickle cell disease: Five tips to help prevent infection.

[29] Lane PA, Buchanan GR, Hutter JJ, Austin RF, Britton HA, Rogers ZR, Eckman JR, DeBaun MR, Wang WC, Matthew P, 2001: Sickle cell disease in children and adolescents: Diagnosis, guidelines for comprehensive care and care paths and protocols for management of acute and chronic complications. Health Resources and Services Administration, Department of Health and Human Services.

[30] Brousseau DC, Owens PL, Mosso AL, Panepinto JA, Steiner CA (2010): Acute care utilization and rehospitalisation for sickle cell disease. JAMA 303:

1288-1294.

Doi:10.1001/jama.2010.378.

PubMed: 20371788.

[31] Bassiouny, M. R., Lamki, Z., Al Elbanna, N., Shah, W. M., \& White, J. M. (2000): Sickle Cell Anemia, A Study from the Capital Area of Oman. Bahrain Medical Bulletin, 17(3). Ndefo, U. A., Maxwell, A. E., Nguyen, H., \& Chiobi, T. L. (2008). Pharmacological management of sickle cell disease. Pharmacy and Therapeutics, 33(4), 238.

To cite this article: Sidieg Sheikheldin Elobied, Ismail A. Ramadan, Ghada S. Abdelmotaleb, Abd elmoniem A.Younis. Study of Common Infections among Children with Sickle Cell Anaemia In Saudi Arabia. BMFJ 2021;38(1): 65-78. DOI: 10.21608/bmfj.2020.25172.1226 